\title{
Vulvar lipoma: So giant and rare?
}

\author{
Ayşegül Karadayı Büyüközsoy (i) and Ömer Aydıner
}

\begin{abstract} discuss the magnetic resonance imaging (MRI) results.

Keywords: Lipoma, Magnetic resonance imaging, Vulva

\section{Background}

Lipomas are the most common benign tumors of soft tissues. They are usually seen on the upper back, abdomen, and extremities [1]. A vulva localization of lipoma is rarely seen. A vulvar lipoma can be misdiagnosed as Bartholin's gland cyst, Nuck canal cyst, or a liposarcoma, so it is important to differentiate a lipoma from these other masses. MRI (magnetic resonance imaging) can be useful for the correct diagnosis [2]. The aim of this case is demonstrated MRI findings of the vulvar lipoma.
\end{abstract}

Background: Lipomas are often small tumors and rarely reach a size larger than $2 \mathrm{~cm}$. Vulvar lipoma is a rare tumor localization, and only a few cases have been reported. It is important to distinguish lipomas from other vulvar masses like liposarcomas, Nuck canal cyst, Bartholin's cyst, and inguinal hernias.

Case presentation: We report on a case of a 43-year-old woman who presented with a giant left vulvar mass and

Conclusions: MRI is useful in evaluating vulvar lipomas and differentiating them from other vulvar pathologies.

\section{Case presentation}

A forty-three-year old woman presented to our hospital due to a slow growing, painless vulvar mass. There was no prior history of vulvar trauma or discharge from the mass. The physical examination revealed a large, single, painless, mobile, exophytic swelling of the left vulva with intact overlying skin, without any change in size on straining or coughing. After examination by a clinician, the patient was referred to our radiology clinic. First, the patient was evaluated with an ultrasonography (US). Sonographic assessment (Toshiba Aplio 500, Toshiba Medical Systems Corporation, Tokyo, Japan) of the mass was performed by using a $12-\mathrm{MHz}$ linear transducer. A

* Correspondence: aysegulkaradayi@hotmail.com

Department of Radiology, İstanbul Kartal Dr. Lütfi Kırdar City Hospital, İstanbul, Turkey pure solid, smoothly contoured, homogeneous isohyperechoic mass without cystic component was detected by US. Color Doppler and power Doppler US imaging did not disclose vascularization within the mass. In the follow-up examination, pelvic MRI (Ingenia $1.5 \mathrm{~T}$, Philips, Amsterdam, The Netherlands) with gadolinium was performed. The patient was placed on the table in the supine position. A body phased-array coil was used. Imaging protocols were turbo spin echo (TSE)-T1-weighted imaging (T1WI) at axial and coronal planes; TSE-T1W fat saturated (FS) at axial planes; TSE-T2-weighted imaging (T2WI) at axial and sagittal planes; TSE-T1WI FS with contrast agent at axial, coronal, and sagittal planes; and diffusion-weighted image (DWI) (b:0-500). The MRI showed a large pedunculated, well-circumscribed, homogeneous fatty mass oriented from the left side of the vulva measuring $11 \times 5 \times 10 \mathrm{~cm}$. The mass is hyperintense at T1WI, hyperintense at T2WI, and hypointense at T2WI FS (Figs. 1 and 2). The mass showed no restriction at DWI (Fig. 3), and there was no enhancement after contrast administration (Figs. 1d and 2c). Several hypointense signals were also evaluated as non-adipose areas at T2WI FS (Fig. 4). As a result of the clinical and imaging findings, the mass was reported as a lipoma. The patient was referred for surgery due to cosmetic reasons and discomfort. The mass was completely removed surgically. The mass, resected, was not attached to underlying

(c) The Author(s). 2021 Open Access This article is licensed under a Creative Commons Attribution 4.0 International License, which permits use, sharing, adaptation, distribution and reproduction in any medium or format, as long as you give appropriate credit to the original author(s) and the source, provide a link to the Creative Commons licence, and indicate if changes were made. The images or other third party material in this article are included in the article's Creative Commons licence, unless indicated otherwise in a credit line to the material. If material is not included in the article's Creative Commons licence and your intended use is not permitted by statutory regulation or exceeds the permitted use, you will need to obtain permission directly from the copyright holder. To view a copy of this licence, visit http://creativecommons.org/licenses/by/4.0/. 


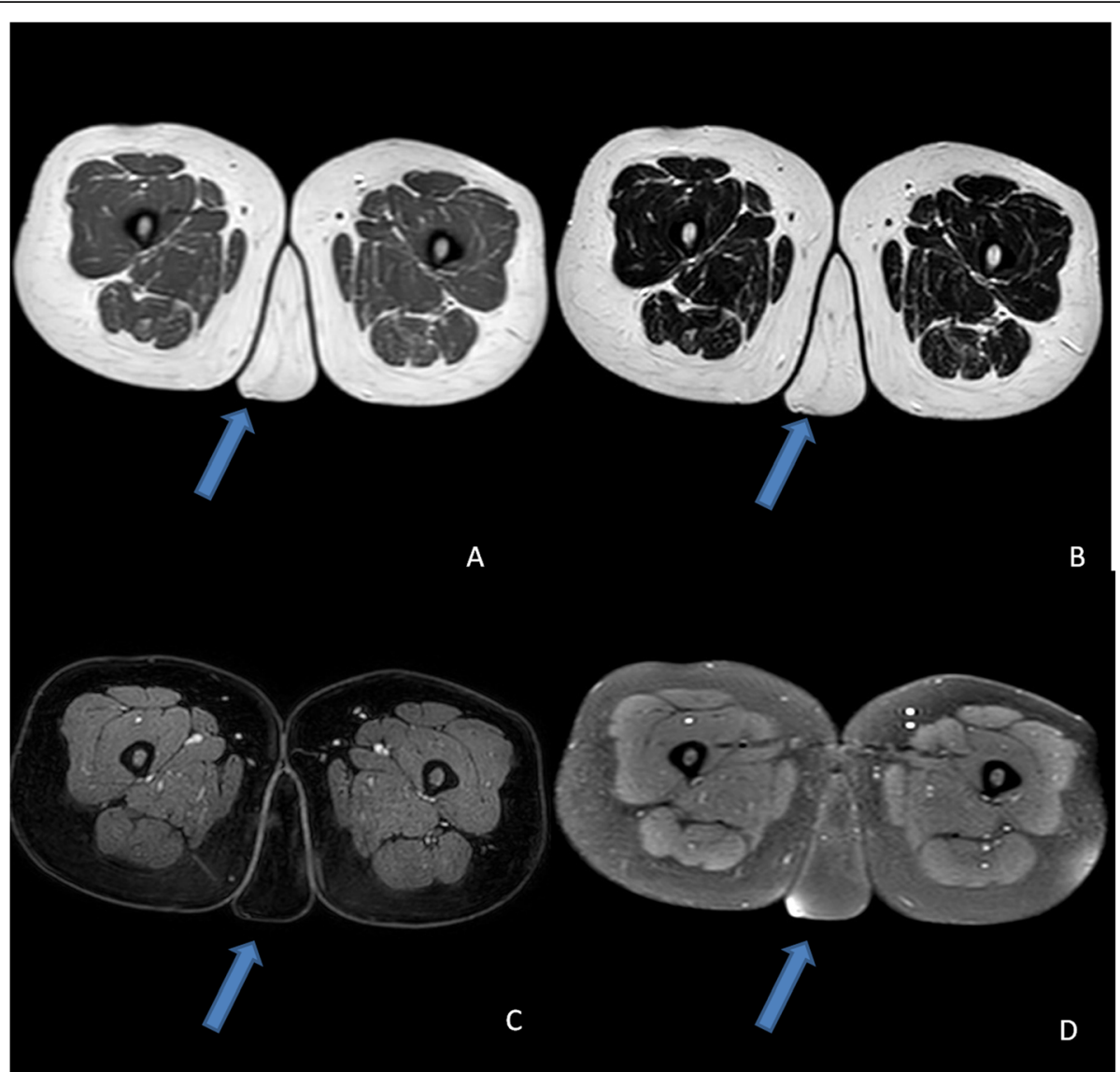

Fig. 1 a. Axial T1Wl obtained through the left labium majus shows a large high-signal mass. b. Axial T2Wl; the mass is hyperintense. c. Axial T2WI with fat saturated; the mass is hypointense homogeneously. $\mathbf{d}$. Axial T1WI with fat saturated and with contrast matter; there is no region contrast matter enhancement in the mass; these signs are typical of a simple lipoma (arrows)

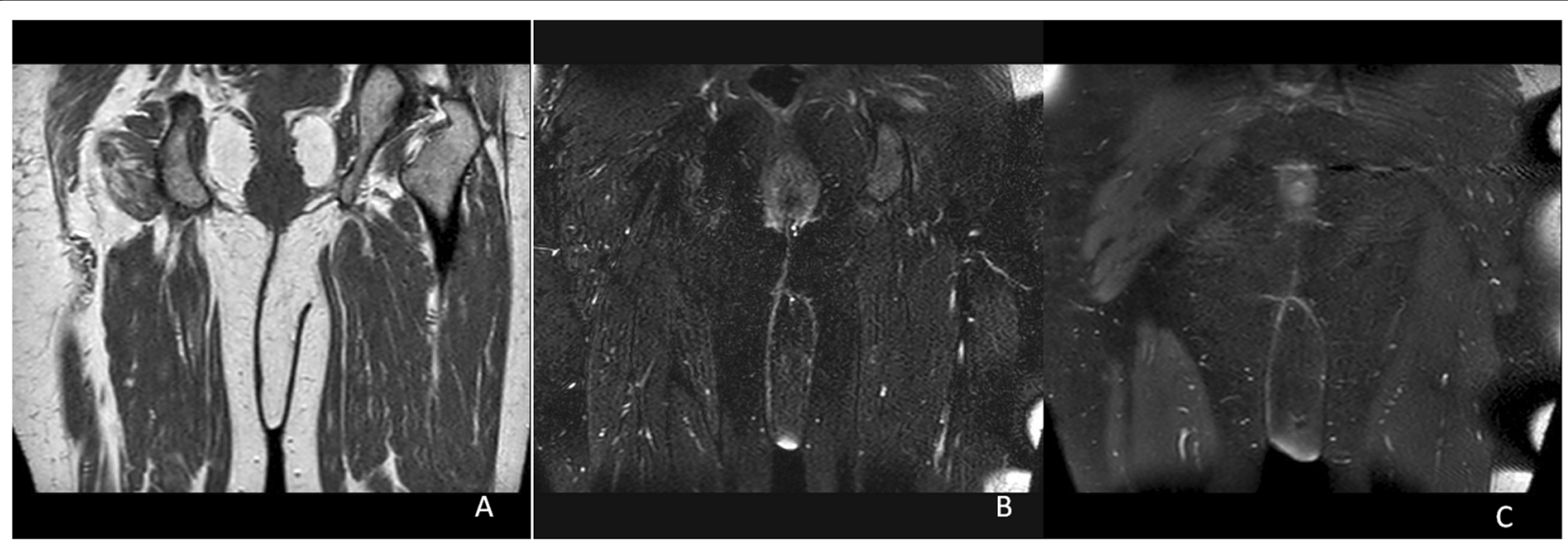

Fig. 2 a. Coronal T1WI; the mass is hyperintense. b. Coronal T2WI with fat saturated; the mass is hypointense. c. Coronal T1WI with fat saturated with contrast matter; there is no region contrast matter enhancement in the mass 


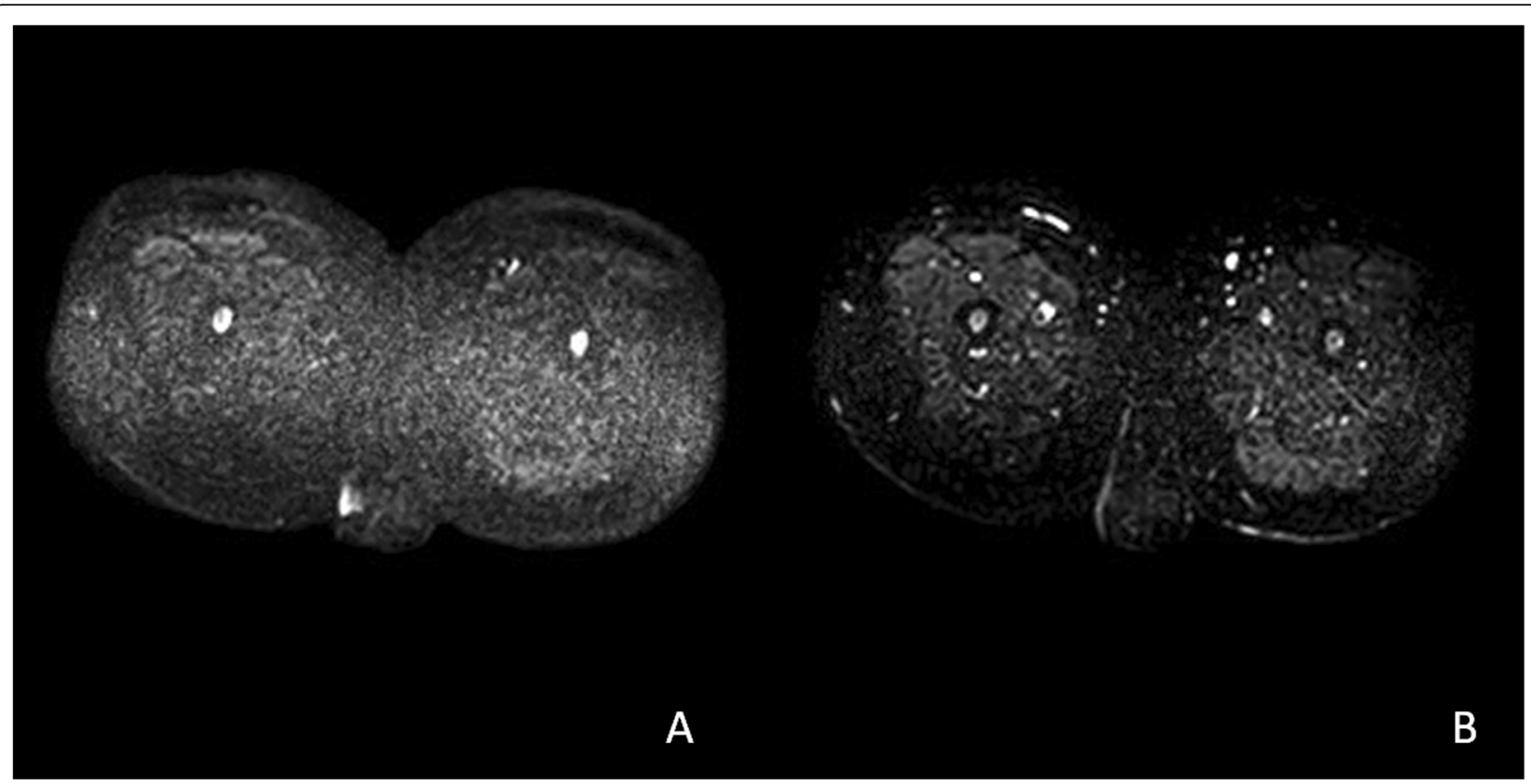

Fig. 3 There is no diffusion restriction on DWI (a) and ADC (b) images

muscle fascia. It was composed of lobulated, slowgrowing, mature adipose tissue, having minimal connective tissue stroma and enclosed in a thin, fibrous capsule with no atypia. Lipoma diagnosis also was confirmed by histopathological findings.

\section{Discussion}

Vulvar lipomas are unusual and giant vulvar lipomas are extremely rare [3]. Vulvar lipomas are rare benign mesenchymal tumors consisting of mature fat cells, often interspersed with strands of fibrous connective tissue [1]. They usually present as slow growing, painless, and mobile soft tissue [4]. Vulvar lipomas must be differentiated from Bartholin's cyst, Nuck canal cyst, inguinal hernia, and liposarcoma [5].

When the clinical diagnosis is not apparent, radiologic techniques, US, computed tomography, and MRI, are useful in differentiating vulvar lipomas $[1,5,6]$. Ultrasound can be helpful to differentiate the cyst, omentum, and intestine tissue $[1,5,6]$. In our case, first, we aimed to differentiate cystic and solid component by ultrasonography. A pure, homogeneous solid component with no cystic component was detected on US. There was no sign of inguinal hernia on clinical examination, so Nuck canal cyst, Bartholin's cyst, and inguinal hernia were not considered in pre-diagnosis.

It is also important for the radiologist to preoperative diagnosis, especially to demonstrate difference between the lipoma and well-differentiated liposarcoma, because simple lipomas are often successfully treated with local excision. Well-differentiated liposarcomas are preferentially treated with wide local excision because of their risk of local recurrence $[2,7,8]$. Gaskin $\mathrm{CM}$ et al. showed that MRI has $100 \%$ specificity to diagnosis lipoma and $100 \%$ sensitivity to diagnosis well-differentiated liposarcomas [2]. Both of them are gross fatty masses, but their prognosis and treatment are not the same. MRI has been described as a useful radiologic method for obtaining the correct diagnosis. Simple lipomas are homogeneous fatty masses; but rarely a non-adiposis component will show up on MRI. Well-differentiated liposarcomas often include thickened or nodular septa, prominent foci of high T2 signal, and prominent areas of enhancement. These finding are associated with non-adipose components $[2,7,8]$. Higher-grade liposarcomas generally do not alter the MRI diagnosis of gross fatty lesions because they typically contain little or no macroscopic fat [2]. In our case, there was a homogeneously fatty vulvar mass without diffusion restriction and contrast enhancement on MRI. These radiological findings supported the diagnosis of lipoma.

Also, simple lipomas may sometimes contain muscle fibers, blood vessels, fibrous septa, and areas of necrosis and inflammation. Due to these contents, they can mimic findings associated with well-differentiated liposarcomas and rarely liposarcoma [2]. Similarly, in our case, there were a few non-adipose areas on MRI.

Clinical information and MRI findings provide helpful information to diagnose lipomas and differentiate from other pathology. Surgical excision is the best treatment for vulvar lipomas, as it allows for exclusion of any malignant components after histopathological examination [9]. 


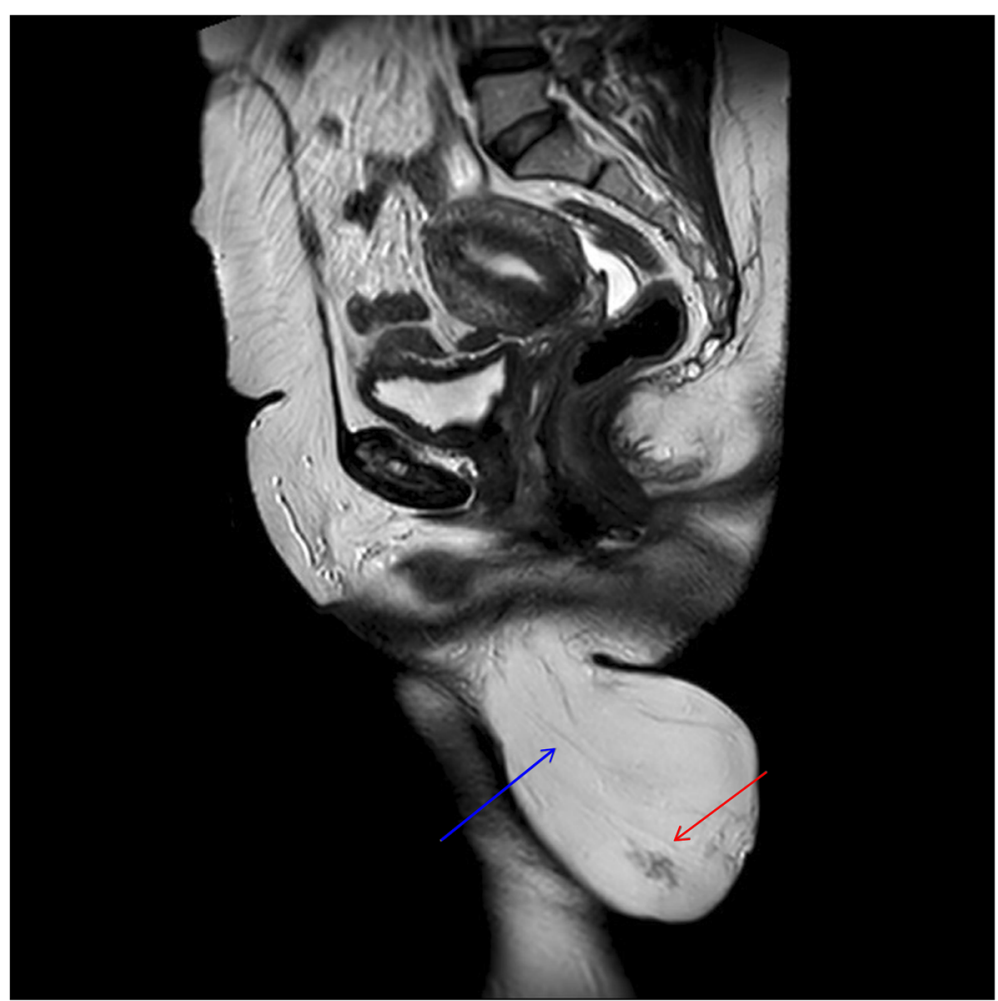

Fig. 4 Sagittal T2Wl; the mass has predominantly high signal intensity with low-signal areas (arrows). The blue arrow shows the thin linear septa; red arrow shows the small nodular areas with decreased signals; they are associated with non-adipose areas that may be seen in the simple lipoma

\section{Conclusion}

It is important to obtain the correct radiologic diagnosis of a vulvar mass due to the importance of the prognosis, treatment, and long-term care. MRI is useful in evaluating vulvar lipomas and differentiating them from the other vulvar pathologies.

\section{Abbreviations}

DWI: Diffusion-weighted image; FS: Fat saturated; MRI: Magnetic resonance imaging; T1WI: T1-weighted imaging; T2WI: T2-weighted imaging; TSE: Turbo spin echo; US: Ultrasonography

\section{Acknowledgements}

There is no acknowledgement for this case.

\section{Authors' contributions}

Concept/design: AKB, ÖA. Literature review: AKB, ÖA. Approval of case: AKB. Critical revision of case: ÖA. Writer: AKB. All authors have read and approved the manuscript.

\section{Funding}

There is no funding for this case.

Availability of data and materials

Not applicable

\section{Declarations}

Ethics approval and consent to participate Not applicable

\section{Consent for publication}

A consent was obtained from the patient by written for case presentation.

\section{Competing interests}

The authors declare that they have no competing interests.

Received: 11 December 2020 Accepted: 11 March 2021

Published online: 23 March 2021

\section{References}

1. Lee JH, Chung SM (2008) Large vulvar lipoma in an adolescent: a case report. J Korean Med Sci 23(4):744-746. https://doi.org/10.3346/jkms.2 008.23 .4 .744

2. Gaskin CM, Helms CA (2004) Lipomas, lipoma variants, and welldifferentiated liposarcomas (atypical lipomas): results of MRI evaluations of 126 consecutive fatty masses. Am J Roentgenol 182(3):733-739. https://doi. org/10.2214/ajr.182.3.1820733

3. Jayi S, Laadioui M, Fatemi HE, Fdili FZ, Bouguern H, Chaara H, Laamarti A, Melhouf MA (2014) Vulvar lipoma: a case report. J Med Case Rep 8(1):203. https://doi.org/10.1186/1752-1947-8-203

4. Kehagias DT, Smyrniotis VE, Karvounis EE, Gouliamos AD, Creatsas G (1999) Large lipoma of the vulva. Eur J Obstet Gynecol Reprod Biol 84(1):5-6. https://doi.org/10.1016/S0301-2115(98)00247-4

5. Oh JT, Choi SH, Ahn SG, Kim MJ, Yang WI, Han SJ (2009) Vulvar lipomas in children: an analysis of 7 cases. J Pediatr Surg 44(10):1920-1923. https://doi. org/10.1016/j.jpedsurg.2009.02.063

6. Sherer DM, Gorelick C, Wagreich A, Lee YC, Serur E, Zigalo A, Abulafia O (2007) Sonographic findings of a large vulvar lipoma. Ultrasound Obstet Gynecol 30(5):786-787. https://doi.org/10.1002/uog.5130

7. Rozental TD, Khoury LD, Donthineni-Rao R, Lackman RD (2002) Atypical lipomatous masses of the extremities: outcome of surgical treatment. Clin Orthop 398:203-211. https://doi.org/10.1097/00003086-200205000-00029 
8. Weiss SW, Rao VK (1992) Well-differentiated liposarcoma (atypical lipoma) of deep soft tissue of the extremities, retroperitoneum, and miscellaneous sites: a follow-up study of 92 cases with analysis of the incidence of "dedifferentiation". Am J Surg Pathol 16(11):1051-1058. https://doi.org/10.1 097/00000478-199211000-00003

9. Odoi AT, Owusu-Bempah A, Dassah ET, Darkey DE, Quayson SE (2011) Vulvar lipoma: is it so rare? Ghana Med J 45:125-127

\section{Publisher's Note}

Springer Nature remains neutral with regard to jurisdictional claims in published maps and institutional affiliations.

Submit your manuscript to a SpringerOpen ${ }^{\circ}$ journal and benefit from:

- Convenient online submission

- Rigorous peer review

- Open access: articles freely available online

High visibility within the field

- Retaining the copyright to your article

Submit your next manuscript at $\boldsymbol{\nabla}$ springeropen.com 